\title{
Test and Computer Modeling of Steel Braces for Earthquake-Resistant Structures: Dual-Core Self-Centering Brace and Sandwiched Buckling-Restrained Brace
}

\author{
Chung-Che Chou, Ying-Chuan Chen \\ Dept. of Civil Engineering, National Taiwan University \\ Center for Earthquake Engineering Research \\ Taipei, Taiwan \\ E-mail: cechou@ntu.edu.tw
}

\author{
Sheng-Yang Chen \\ Dept. of Civil Engineering, National Chiao Tung \\ University \\ Hsinchu, Taiwan
}

\begin{abstract}
This work presents mechanics, tests, and finite element modeling results of a proposed steel dual-core selfcentering brace (SCB) and a sandwiched buckling-restrained brace (BRB) for earthquake-resistant structures. The mechanics and cyclic behavior of these two braces are first explained, followed by testing of dual-core SCBs and BRBs to evaluate their cyclic performances. Finite element modeling analysis is then performed on the specimens to further verify the capability of the computer modeling for the mechanics and hysteretic responses of specimens observed in tests.
\end{abstract} BRB

Keywords-computer modeling; dual-core SCB; sandwiched

\section{INTRODUCTION}

This work presents the mechanics, seismic tests, and computer modeling analyses of two new steel braces for earthquake-resistant structures. The first brace is called a dual-core self-centering brace (SCB), which applies posttensioning (PT) technology in the brace not in the beam to reduce the restraint from columns and slabs $[1,2]$, as well as the residual drift of structures. A dual-core SCB [3, 4] consists of conventional steel bracing members, energy dissipative devices, and two tensioning element sets that are in a parallel arrangement to enhance its axial deformation capacity. Three 5350-mm long dual-core SCB, fabricated by a local steel fabricator, were tested to evaluate their performances at the National Center for Research on Earthquake Engineering (NCREE), Taiwan, with those results presented in this paper. The second brace is called as a sandwiched buckling-restrained brace (BRB), which sandwiches a core plate using a pair of restraining members with high-strength ASTM A490 bolts to expedite the assembly process and provide opportunities for the inspection of the core after large earthquakes. Tests were conducted on four proposed BRBs and BRB frames [5-7] designed with moment of inertia of the restraining member, number and spacing of ASTM A490 bolts. Finally, several finite element analyses using the computer program ABAQUS [8] were conducted on the specimens to perform a correlation study and to verify if the computer modeling technique can be used to simulate the cyclic behaviors of specimens under cyclic loading.

\section{MECHANICS OF A DuAL-CORE SCB}

Fig. 1 shows the proposed dual-core SCB, which consists of three steel bracing members, two PT element sets, energy dissipation devices, and end plates. Three steel bracing members are designated as the first core, second core, and outer box; all members have the same length. An energy dissipative device, which is located at the one end of the brace, is activated by the relative motion induced between the first core and outer box. All bracing members, end plates, and tendons in the dual-core SCB are arranged so that a relative motion induced between these bracing members causes serial elongation of the inner and outer tendons to achieve the desired brace elongation or shortening, which is always two times that of the tendon elongation (Fig. 2(a)).

External loads from a building subjected to earthquake loading are applied on both ends of the brace (Fig. 2(a)). Once the activation load, $F_{d t}$, of a dual-core SCB is exceeded, the inner end plate moves in the same direction with respect to the outer end plate. The activation load, $F_{d t}$, is expressed as

$$
F_{d t}=\frac{n T_{i n}}{2}+F_{f}
$$

where $T_{i n}$ is the initial PT force in one tendon, $F_{f}$ is the frictional force of the energy dissipative device, and $n$ is the total number of tendons. Axial stiffness of the dual-core SCB changes from the axial stiffness of these bracing members to the postelastic stiffness, as determined by the axial stiffness of tendons and second core:

$$
K_{p t}=\frac{1}{\frac{1}{\frac{n}{2} K_{t}}+\frac{1}{\frac{n}{2} K_{t}}+\frac{1}{K_{2 c}}}
$$

where $K_{2 c}$ is the axial stiffness of the second core and $K_{t}$ is the axial stiffness of one tendon. The elongation in each tendon set $\delta$ causes the axial deformation of $2 \delta$ in the dualcore SCB. The brace returns to its original position when the load is removed (Fig. 2(b)). The behavior of the brace under compression is similar to that under tension. 


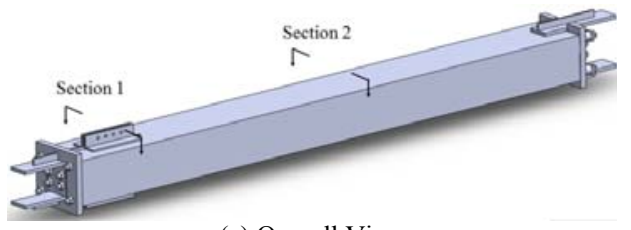

(a) Overall View

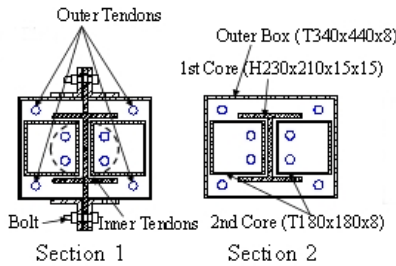

(b) Section View

Figure 1. A proposed dual-core SCB

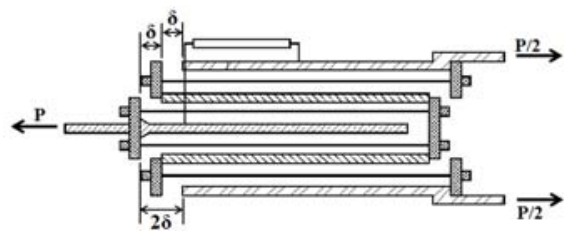

(a) Brace Kinematics

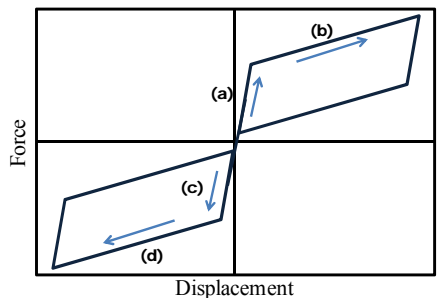

(b) Force versus Displacement Relationship

Figure 2. Kinematics and hysteretic response of a proposed dual-core SCB

\section{TEST Results OF A DUAl-Core SCB}

Three dual-core SCB specimens were tested using the setup shown in Fig. 3(a). The specimen was positioned in the test setup, which included a steel box column with a pinconnection to the floor and two $1000-\mathrm{kN}$ hydraulic actuators. Each dual-core SCB had a first core of $\mathrm{H} 230 \times 210 \times 15 \times 15$ $\mathrm{mm}$, two second cores of $\mathrm{T} 180 \times 180 \times 8 \mathrm{~mm}$, and an outer box tube of $\mathrm{T} 340 \times 440 \times 8 \mathrm{~mm}$. The hysteretic response of one specimen is shown in Fig. 3(b). The dual-core SCB subjected to AISC standard loading protocol for testing the BRB [9] developed stable energy dissipation and self-centering property up to an interstory drift of $2 \%$. No damage in PT elements or steel bracing members was found throughout the test. As mentioned in the previous section, the inner end plate seperated with respect to the outer end plate after activation (Fig. 2(a)). The specimen was then tested at a fixed drift of $1.5 \%$ for 15 cycles and an increasing cyclic loading up to a drift of $2.5 \%$; completely repeatable flagshaped responses with low residual drifts were observed in all tests. Information regarding cyclic test results of other dual-core SCBs can be found elsewhere [10].

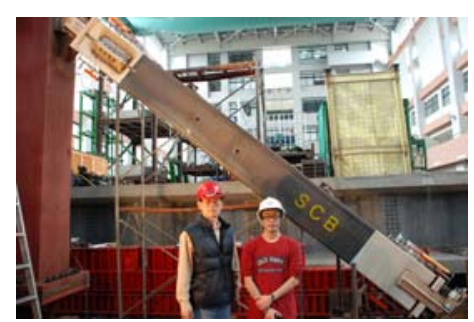

(a) Setup

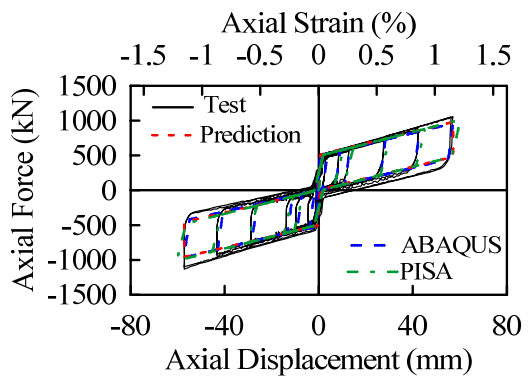

(b) Hysteretic Response

Figure 3. Cyclic test of a dual-core SCB

\section{SANDWICHED BRB}

A sandwiched BRB (Fig. 4) eliminates the use of the unbonded material in manufacturing and increases design alternatives of the core plate for connecting gusset plates [57]. Two identical restraining members are formed by welding a channel to a face plate and then filled with mortar. The benefit of using the proposed sandwiched BRB is the ability to disassemble the brace in the field, which not only means that the core plate can be replaced independently of the restraining members, but also provides an opportunity for inspection of the core after large earthquakes. This is needed if the BRB is used in a bridge superstructure where the highcycle fatigue property is a concern in design. In case the core plate is damaged, replacing the core plate with original restraining members of the sandwiched BRB is much cheaper than other conventional BRBs. Based on the limit state of global stability of the BRB, the maximum compressive load is:

$$
P_{\text {max }, g}=\frac{M_{p}^{g}}{i+g+e+\frac{M_{p}^{g}}{P_{e}}}
$$

where $M_{p}^{g}$ is the plastic moment capacity of two restraining members, $i$ is the initial imperfection at the center of the $\mathrm{BRB}, g$ is the gap between the core and restraining member, $e$ is the eccentricity at the BRB end, and $P_{e}$ is the Euler buckling load of the restraining member. The maximum compressive load based on a limit state of local stability of the $\mathrm{BRB}$ is

$$
P_{\max , l}=\frac{M_{p}^{l} L_{w}}{g L_{b}}
$$



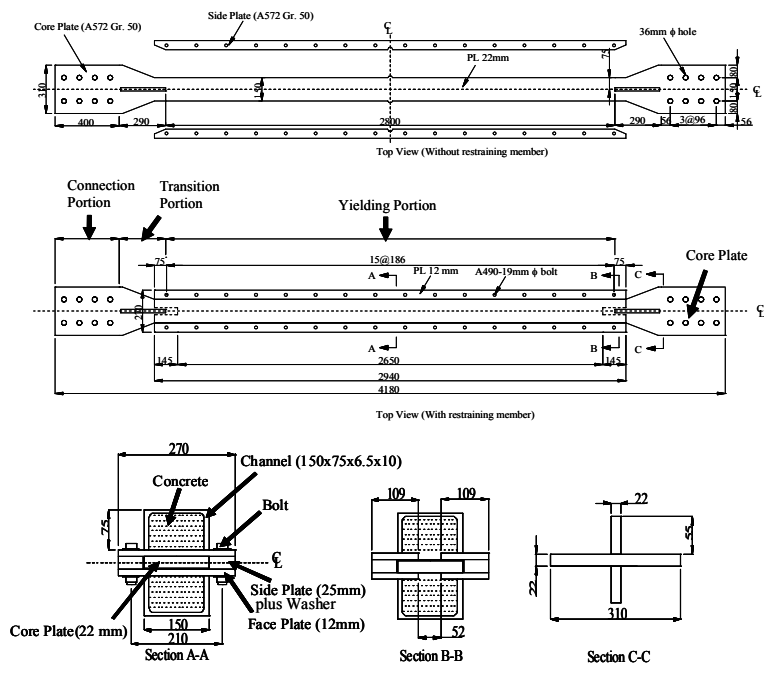

Figure 4. Sandwiched BRB (unit: $\mathrm{mm}$ )

\section{Test Results of A SANDwiched BRB}

Cyclic tests of four sandwiched BRB specimens were performed. Presented here is a typical hysteretic behavior of the BRB under cyclic loading. Fig. 4 shows a typical dimension of one specimen tested. Other specimens were identical to this specimen, except for the size of restraining members and number of bolts. All specimens were tested using the same test setup as shown in Fig. 3(a) for the dualcore SCB. Each specimen was positioned at an inclination of $\theta=50^{\circ}$ in the test setup. This specimen exhibited stable hysteretic responses up to a core strain of $2.1 \%$ during the standard loading test [Fig. 5(a)]. No yielding or buckling of the restraining member was observed after the test. The specimen was then subjected to low-cycle fatigue tests until failure. Cumulative ductility for all tests was 804, significantly larger than 200 specified in 2010 AISC seismic provisions [9]. The specimen was disassembled by removing all bolts. A fracture was identified near the center of the core [Fig. 5(b)]; the restraining members were undamaged throughout the test.

\section{COMPuter MOdeling FOR THE SCB AND BRB}

\section{A. Dual-Core SCB}

To further study the self-centering behavior of dual-core $\mathrm{SCBs}$, an analytical study using the finite element (FE) computer program ABAQUS [8] was conducted on the specimen for simulation. The dual-core SCB specimen described in the previous section was first analyzed. All steel bracing members and end plates were modeled using eight-node solid elements, C3D8R. Material nonlinearity with the von Mises yielding criterion was used in the steel bracing members. A tendon made of FRP composites was modeled with linearly elastic properties. Fig. 6(a) shows a three-dimensional model of the specimen after assembly.
Axial displacement obtained from the test was used as a controlling parameter in the finite element analysis.

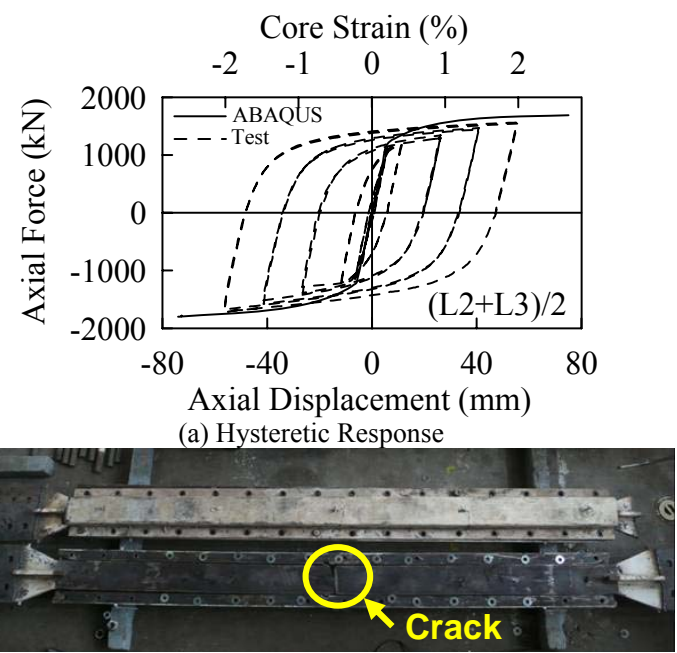

(b) Removal of restraining members after 21 cycles of fatigue loading test at a core strain of $1.6 \%$

Figure 5. Comparison between test and finite element analysis

When the axial force in the brace exceeds the activation load, the inner and outer end plates begin to move with respect to the bracing members. Figure 6(b) shows that the brace in tension produces a relative displacement between the left inner end plate and the outer box, $\Delta_{2}$, twice that between the left outer end plate and the outer box, $\Delta_{1}$. Opening behavior observed on the right end in compression is similar to that observed on the left end in tension. Fig. 3(b) shows that the specimen in the first cyclic test performs as the prediction by the finite element computer model.

\section{B. Sandwiched BRB}

A model using the finite element (FE) computer program ABAQUS [8] was also conducted on the BRB specimen. Material nonlinearity with the von Mises criterion was applied to the steel core and restraining members. Concrete was modeled with an elastic property. The eightnode solid element, C3D8R, modeled a steel core, two restraining members, concrete, and bolts. Because no slippage occurred between the core and restraining members in specimens, rigid link elements modeled each bolted connections. A hard contact behavior, allowing separation of both interfaces in tension and no penetration of that in compression, modeled the interaction between the steel core and two restraining members. Fig. 7 shows a close up and cross-section of the BRB before and after assembly. An initial imperfection of the core was used by scaling the first buckling mode of the core obtained from the FE analysis. An axial displacement was applied to the core to obtain the monotonic behavior. The specimen had no global buckling at an axial core strain of $2.2 \%$ [Fig. 5(a)]. Generally speaking, the FE model proposed in this study predicted well the elastic axial stiffness and post-yield strength of the sandwiched BRB from the test. 


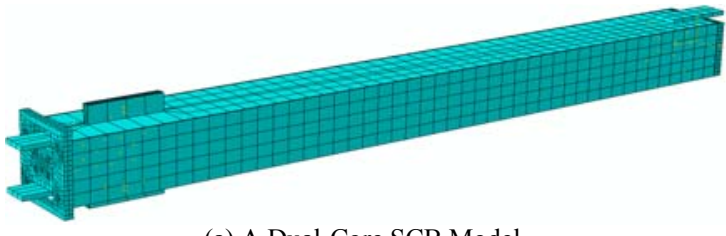

(a) A Dual-Core SCB Model

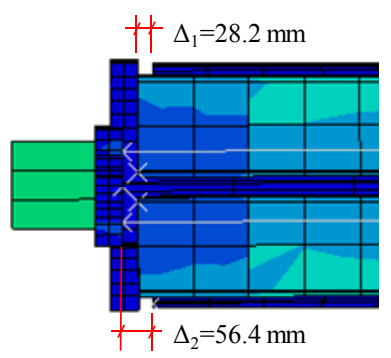

(b) A Dual-Core SCB Model in Tension

Figure 6. Computer model of a dual-core SCB
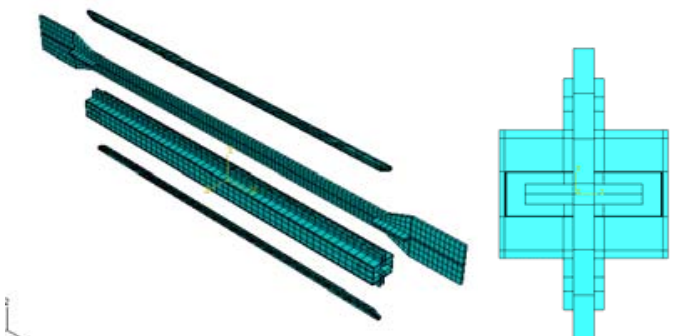

Figure 7. Computer model of a sandwiched BRB

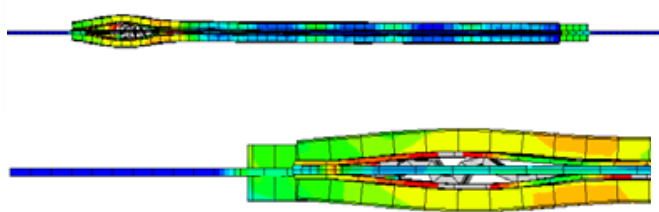

(a) Local Buckling

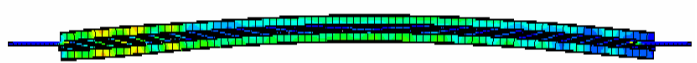

(b) Global Buckling

Figure 8. Global and local buckling of computer models for BRBs

For demonstrating the technique of BRB modeling, two sandwiched BRBs were designed to buckle locally and globally. Local buckling of the restraining members between two fully-tightened bolts was caused by high-mode buckling of the core [Fig. 8(a)]. The second model showed global buckling of the sandwiched BRB with the core and restraining member caused by a low buckling-to-yield load ratio [Fig. 8(b)].

\section{CONCLUSIONS}

This work presents tests and computer modeling analysis results of a new dual-core self-centering brace (SCB) and sandwiched BRB. The dual-core SCB is composed of three steel bracing members for compression, two sets of tensioning elements for self-centering capability, and friction devices for energy dissipation. Validation tests were performed on the 5350-mm long dual-core SCB with GFRP tensioning elements. The sandwiched BRB is composed of a core plate for axial load resistance and two restraining members for providing lateral restraint to the core plate under compression.

Tests and finite element analyses confirmed that the dualcore SCB performs as predicted by the mechanics. The proposed dual-core SCB reduces the need for tendons with high elongation capacity, so widely varying tendons can be used as re-centering elements. Tests and finite element analyses also confirmed that the sandwiched BRB can perform well under cyclic loads. Global and local buckling behaviors of the sandwiched BRB can also be evaluated by using the finite element computer program. More information on the proposed dual-core SCB and sandwiched $\mathrm{BRB}$ can be found elsewhere $[5,11]$.

\section{ACKNOWLEDGMENT}

The financial support provided by the National Science Council, National Taiwan University, and NCREE, Taiwan is appreciated.

\section{REFERENCES}

[1] Chou C-C, Weng C-Y, Chen J-H. 2008. Seismic design and behavior of post-tensioned connections including effects of a composite slab. Engineering Structures, 30, pp. 3014-3023.

[2] Chou C-C, Chen J-H. 2010. Column restraint in post-tensioned selfcentering moment frames. Earthquake Engineering and Structural Dynamics, 39(7), 751-774.

[3] Chou C-C, Chen Y-C, Pham D-H, Truong V-M. 2012. Experimental and analytical validation of steel dual-core self-centering braces for seismic-resisting structures. 9th International Conference on Urban Earthquake Engineering/4th Asia Conference on Earthquake Engineering, March 6-8, Tokyo, Japan.

[4] Chou C-C, Chen Y-C, Chung P-T. 2012. Dual-core self-centering energy dissipation brace apparatus. US Patent No. 8316589 B2, National Applied Research Laboratories, United States Patent and Trademark Office, USA.

[5] Chou C-C, Chen S-Y. 2010. Subassemblage tests and finite element analyses of sandwiched buckling-restrained braces. Engineering Structures, 32, 2108-2121.

[6] Chou C-C, Liu J-H. 2012. Frame and brace action forces on steel corner gusset plate connections in buckling-restrained braced frames. Earthquake Spectra, 28(2), 531-551.

[7] Chou C-C, Liu J-H, Pham D-H. 2012. Steel buckling-restrained braced frames with single and dual corner gusset connections: seismic tests and analyses. Earthquake Engineering and Structural Dynamics, 7(41): 1137-1156.

[8] HKS, 2009. ABAQUS User's Manual Version 6.9, Hibbitt, Karlsson \& Sorensen, Pawtucket, RI.

[9] AISC (2010). Seismic provisions for structural steel buildings. American Institute of Steel Construction, Chicago, IL. 
[10] Chou C-C, Chen Y-C. 2012. Development and seismic performance of steel dual-core self-centering braces. 15th World Conference on Earthquake Engineering, September 24-28, Lisbon, Portugal.
[11] Chou C-C, Chen Y-C. 2012. Development of steel dual-core selfcentering braces: quasi-static cyclic tests and finite element analyses. Earthquake Spectra (2012/5 accepted, 082712EQS272M). 